\title{
On your mark, get set: Brainstem circuitry underlying saccadic initiation'
}

\author{
D.P. Munoz, M.C. Dorris, M. Paré, and S. Everling
}

\begin{abstract}
Saccades are rapid eye movements that are used to move the visual axis toward targets of interest in the visual field. The time to initiate a saccade is dependent upon many factors. Here we review some of the recent advances in our understanding of the these processes in primates. Neurons in the superior colliculus and brainstem reticular formation are organised into a network to control saccades. Some neurons are active during visual fixation, while others are active during the preparation and execution of saccades. Several factors can influence the excitability levels of these neurons prior to the appearance of a new saccadic target. These pre-target changes in excitability are correlated to subsequent changes in behavioural performance. Our results show how neuronal signals in the superior colliculus and brainstem reticular formation can be shaped by contextual factors and demonstrate how situational experience can expedite motor behaviour via the advanced preparation of motor programs.
\end{abstract}

Key words: superior colliculus, reticular formation, eye movement, saccade, motor preparation, motor control.

Résumé : Les saccades sont des mouvements rapides des yeux utilisés pour diriger l'axe visuel vers des cibles d'intérêt du champ visuel. Le temps de déclenchement d'une saccade dépend de nombreux facteurs. Nous révisons ici quelques progrès récents dans notre compréhension de ces processus chez les primates. Les neurones du colliculus supérieur et de la formation réticulaire du tronc cérébral sont organisés en un réseau pour contrôler les saccades. Certains neurones sont actifs durant la fixation visuelle, alors que d'autres sont actifs durant la préparation et l'exécution des saccades. Plusieurs facteurs peuvent influencer les niveaux d'excitabilité de ces neurones avant l'apparition d'une nouvelle cible saccadique. Ces variations d'excitabilité pré-cibles sont corrélées aux modifications subséquentes de la performance. Nos résultats montrent comment les signaux neuronaux dans le colliculus supérieur et la formation réticulaire du tronc cérébral peuvent être modulés par des facteurs contextuels; ils démontrent aussi comment une expérience situationnelle peut faciliter le comportement moteur au moyen de programmes moteurs préétablis.

Mots clés : colliculus supérieur, formation réticulaire, mouvement des yeux, saccade, préparation motrice, contrôle moteur.

[Traduit par la Rédaction]

\section{Introduction}

One of the fundamental functions of the central nervous system is the generation of motor responses to sensory stimulation. The visual guidance of saccadic eye movements represents one form of sensory-to-motor transformation that has provided significant insights in our understanding of sensory-motor processing, movement control, and the pathophysiology of visual and gaze disorders (Leigh and Zee 1999). The eyes have a simple, yet well defined repertoire of movements. Moreover, our knowledge of the brainstem circuitry controlling eye movements is now adequate to provide

Received March 8, 2000. Published on the NRC Research Press web site on October 19, 2000.

D.P. Munoz, ${ }^{2}$ M.C. Dorris, M. Paré, and S. Everling. MRC Group in Sensory-Motor Neuroscience, Department of Physiology, Queen's University, Kingston, ON K7L 3N6, Canada.

${ }^{1}$ This paper has undergone the Journal's usual peer review process.

${ }^{2}$ Author for all correspondence at Department of Physiology, Queen's University, Kingston, ON K7L 3N6, Canada (e-mail: doug@eyeml.queensu.ca). a basis for understanding how saccades are produced. The goal of this article is to review recent advances in our understanding of the neural processes involved in the initiation of saccadic eye movements in primates.

\section{Background}

The primate retina has a specialised region, called the fovea, which serves the central portion of the visual field and provides the greatest acuity (Perry and Cowey 1985). In most cortical and sub-cortical visual areas, the fovea has the greatest representation, emphasising its importance in visual processing (Dow et al. 1981; Van Essen et al. 1984). Saccades are rapid eye movements used to redirect the visual axis, bringing successive visual images of interest onto the fovea. A fixation mechanism complements this visual tracking to keep the visual images steady on the foveae for detailed analysis. This alternating saccade-fixate behaviour is repeated several hundred thousand times a day, thereby making it essential for the execution of everyday tasks, including reading this article.

There is an extensive body of literature describing many characteristics of the various areas in the primate brain that are involved in vision, visual fixation, and saccade production. These areas span most of the neuraxis, including regions of 
Fig. 1. (A) Coordinates of the saccadic motor map in the superior colliculus (SC). Each point codes for a unique direction and amplitude as shown by the vectors from the six representative sites in the left SC. Small saccades are represented rostrally, large saccades caudally, upward saccades medially, downward saccades laterally. Visual fixation is represented in the extreme rostrolateral pole. (B) Extracellular recording of action potentials (represented by rasters) from a fixation neuron (FN) in the rostral SC and a saccade neuron (SN) in the caudal SC when a monkey generates a contraversive saccade. (C) Schematic model of how the SC controls visual fixation and saccade generation. Higher inputs from several cortical areas, basal ganglia, and other brain areas converge onto the SC motor map to selectively activate populations of FN or SN. A network of lateral inhibitory connections within the SC sharpens the signals at the level of the SC, and a subset of FN and SN project to the reticular
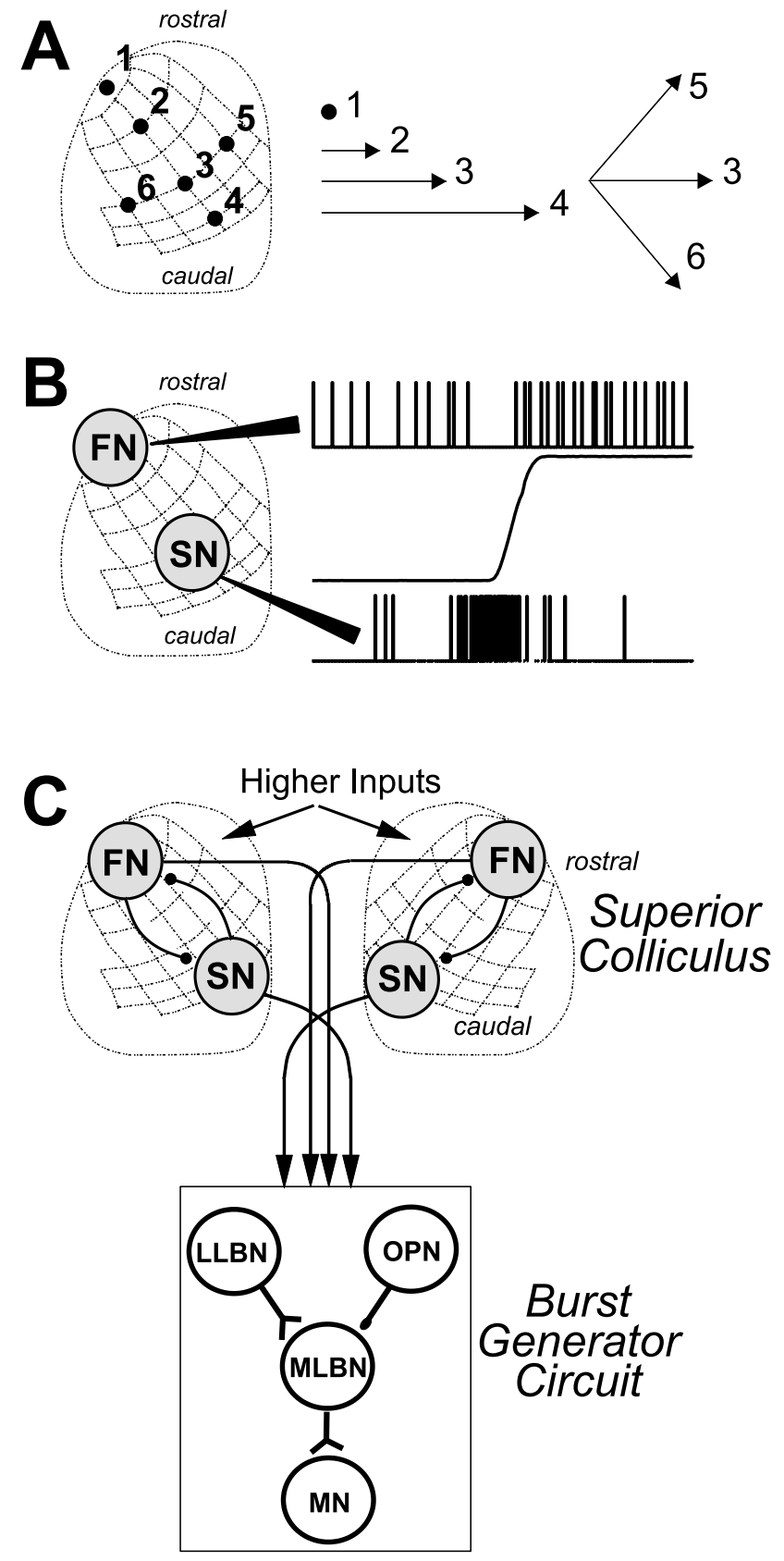

formation to influence the pre-motor burst generator circuit: long-lead burst neuron (LLBN), omnipause neuron (OPN), medium-lead burst neuron (MLBN), motoneuron (MN).

the parietal and frontal cortices, basal ganglia, thalamus, superior colliculus, cerebellum, and brainstem reticular formation (Wurtz and Goldberg 1989; Leigh and Zee 1999). Neurological immaturity, degeneration, or malfunction may influence the ability of a subject to maintain visual fixation and generate accurate saccades. Indeed, many neurological and psychiatric disorders are accompanied by disturbances in visual fixation and eye movements and these have become important cues in the identification of affected brain regions.

\section{Neuronal circuitry: Superior colliculus and reticular formation}

The superior colliculus (SC), a laminated structure in the dorsal mesencephalon, plays a critical role in the interplay between visual fixation and saccadic eye movements. The dorsal-most superficial layers of the SC contain neurons that receive direct retinal inputs as well as inputs from other visual areas (Robinson and McClurkin 1989). As in the many cortical visual areas, these SC neurons have well defined visual receptive fields and are organised into a topographically coded map of the contralateral visual hemifield.

In contrast, the intermediate layers of the SC contain neurons whose discharges are correlated with saccadic eye movements and visual fixation (Glimcher and Sparks 1992; Mays and Sparks 1980; Mohler and Wurtz 1976; Moschovakis et al. 1988b; Munoz and Guitton 1989, 1991; Munoz et al. 1991 $a, b$; Munoz and Wurtz 1993a, 1995a; Schiller and Koerner 1971; Sparks 1978; Sparks and Mays 1980; Sparks et al. 1976; Waitzman et al. 1991; Wurtz and Goldberg 1971, 1972). These neurons are organised into a two-dimensional motor map coding for saccades directed to the contralateral visual field (Fig. 1A). Neurons increasing their discharges before and during saccades, the saccade-related neurons (SN; Fig. 1B), are distributed throughout these intermediate layers. Neurons exhibiting tonic discharges during visual fixation and a pause during most saccades, the fixation-related neurons (FN; Fig. 1B), form a continuum with the SNs and are restricted mostly to the rostro-lateral end of the motor map underneath the superficial layer's representation of the fovea. FN have been prescribed a role in the maintenance of active visual fixation (Munoz and Wurtz 1993a, b), however, they may also participate in the execution of microsaccades (Munoz and Wurtz 1993a, 1995b; Gandhi and Keller 1999a), smooth pursuit (Krauzlis et al. 1997), and vergence eye movements (Chaturvedi and Van Gisbergen 2000). Local inhibitory connections may help shape the reciprocal activity patterns of SN and FN (Munoz and Guitton 1989, 1991; Munoz and Wurtz 1993b, 1995b). The recent finding that most SN and FN are inhibited at very short latency after microstimulation of remote collicular regions (Munoz and Istvan 1998) provides credence to this hypothesis. Additional selective activation could be provided by inputs that converge upon these SC neurons from the cerebral cortex (Segraves and Goldberg 1987; Paré and Wurtz 1997; Everling and Munoz 2000), 
Fig. 2. (A) Gap saccade paradigm. The fixation point (FP) appears in the centre of the screen and then disappears. There is a gap period during which no stimuli are present which precedes the appearance of an eccentric saccadic target $(\mathrm{T})$. The monkey is required to make a saccadic eye movement (E) to the eccentric target after it appears. The gap period is either varied randomly from $0-800 \mathrm{~ms}$ or fixed at $200 \mathrm{~ms}$ and the target appears randomly at one of two mirror image positions. B and C) distribution of saccadic reaction times (SRT) obtained from a monkey during 0 ms gap trials (B) and $200 \mathrm{~ms}$ gap trials (C). Additional details of methodology, results, and interpretation are provided in Paré and Munoz (1996).
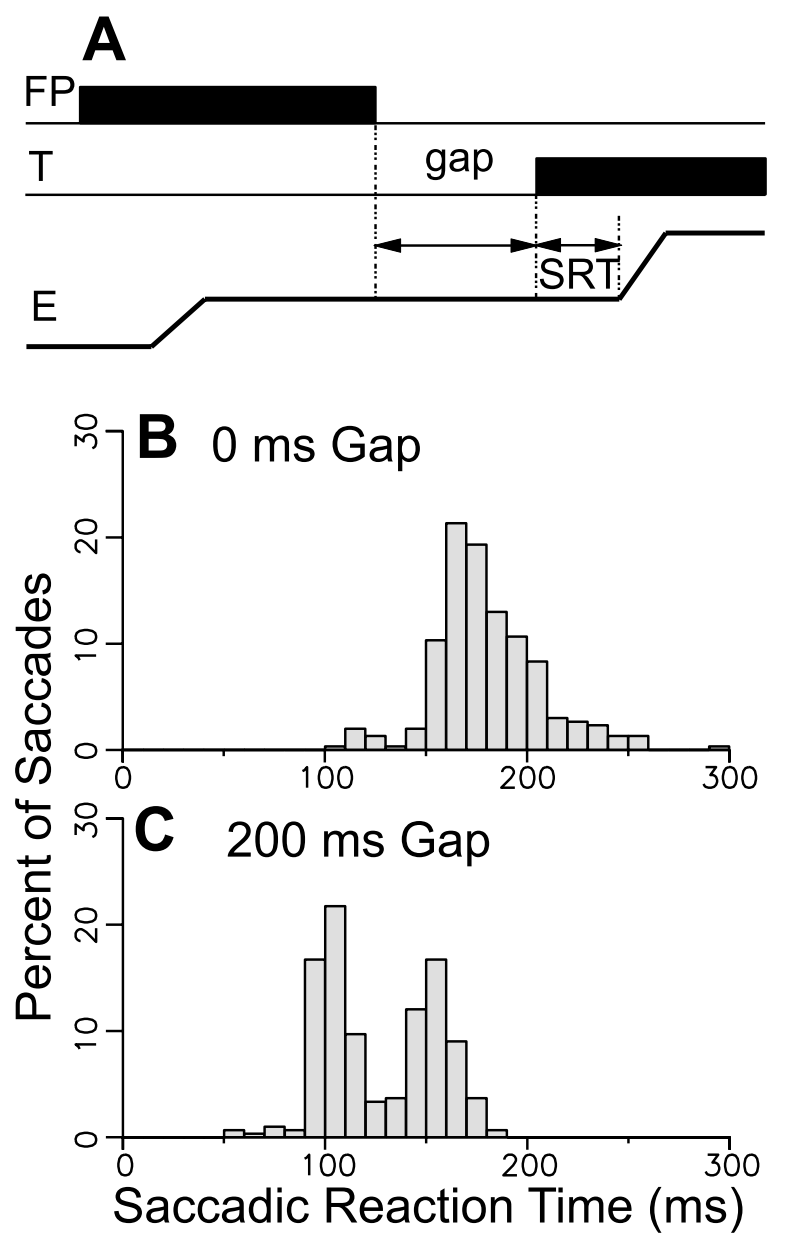

basal ganglia (Hikosaka and Wurtz 1983), and other brain areas. Fixation and saccade signals may be integrated within the SC and then transmitted to the burst generator circuit in the reticular formation (Fig. 1C) to dictate fixation and saccade behaviours.

Both FN and SN have been shown to project directly to neurons within the burst generator circuit located in the reticular formation (Istvan et al. 1994; Moschovakis et al. $1988 a, b$; Scudder et al. 1996; Gandhi and Keller 1997). The organisation and properties of this pre-motor circuit (Fig. 1C) responsible for activating the ocular motoneurons have been reviewed elsewhere (Fuchs et al. 1985; Hepp et al. 1989; Keller 1991; Moschovakis et al. 1996). Briefly, the long-lead burst neurons (LLBN) and omnipause neurons
(OPN) receive potent monosynaptic SC excitatory inputs that are presumed to originate primarily from SN and FN, respectively (Raybourn and Keller 1977; Paré and Guitton 1994; Büttner-Ennever et al. 1999; Gandhi and Keller $1999 b$ ). Accordingly, these neurons display activity patterns similar to those seen in the SC. The LLBN discharge a saccade-related burst of action potentials preceded by lowfrequency activity, whereas the OPN display a tonic discharge for all fixation periods and a pause during all saccades (Luschei and Fuchs 1972; Keller 1974; Raybourn and Keller 1977; Strassman et al. 1987; Everling et al. 1998b). Ultimately, saccades are generated by a pulse of activity in the agonist (increase) and antagonist (decrease) ocular muscles provided by motoneurons (MN), which are respectively produced by excitatory and inhibitory medium-lead burst neurons (MLBN). The MLBN only discharge a discrete burst of action potentials time-locked to the saccade onset which is hypothesized to originate from the LLBN (Scudder 1988), whose low-frequency activation may be filtered out by the potent monosynaptic inhibition from the OPN. As a consequence, OPN must be silenced each time a saccade is produced.

There is an important distinction between the code used by the SC and the reticular formation to control saccade execution. Saccade metrics are coded spatially in the SC, with each SN being optimally active for a specific range of saccade direction and amplitude that define a movement field (Wurtz and Goldberg 1971, 1972; Sparks et al. 1976; Sparks and Mays 1980; Munoz and Wurtz 1995a). Upward, downward, leftward, and rightward saccades in the reticular formation are represented by different populations of MLBN, and the amplitude of saccades in the preferred directions of each MLBN are coded temporally (Van Gisbergen et al. 1981; Fuchs et al. 1985; Hepp et al. 1989; Cullen and Guitton 1998). Mechanisms for this spatiotemporal transformation have been proposed (Hepp and Henn 1983; Moschovakis et al. 1998) and debated (Quaia and Optican 1998).

\section{The gap saccade paradigm: A tool for studying saccadic initiation}

Several behavioural paradigms have been developed to investigate the neural processes involved in saccade initiation. One of them includes the gap saccade task originally designed by Saslow (1967) and illustrated in Fig. 2A. Each trial is initiated by the appearance of a central fixation point. After a period of visual fixation, the fixation point disappears leaving the subject momentarily in complete darkness (the gap period) until an eccentric visual target appears. The subject is required to maintain central fixation during the gap period and to initiate a targeting saccade only after the detection of the visual target. The disappearance of the fixation point somehow can both release the fixation system and act as a temporal warning signal allowing the subject to prepare for the impending target appearance (Ross and Ross 1980; Reuter-Lorenz et al. 1991; Jüttner and Wolf 1992; Kingstone and Klein 1993; Dorris and Munoz 1995; Paré and Munoz 1996). Therefore, the introduction of a gap period (e.g., $200 \mathrm{~ms}$ ) leads to a general reduction in saccadic reaction time (SRT), known as the gap effect (Fig. 2B,C). In 
Fig. 3. Examples of recording from SCFN, SCBUN and SCBN in the SC and OPN, LLBN and MLBN in the reticular formation while a monkey performs the gap saccade task. Each panel shows, from top to bottom, the discharge of a neuron during several trials (each tic mark is an action potential and each row is a single trial), the spike density waveform representing the probability of discharge of the neuron at a given moment in time, the individual eye position traces from the same trials, and traces representing the timing of target stimuli. Each condition starts with the monkey fixating a central fixation point (FP). In the gap saccade task, the FP disappears (left vertical dashed line) $200 \mathrm{~ms}$ before an eccentric target (T) appears (right vertical dashed line) and the monkey the orients to the T. Additional details are provided in Dorris et al. (1997) and Everling et al. (1998a).

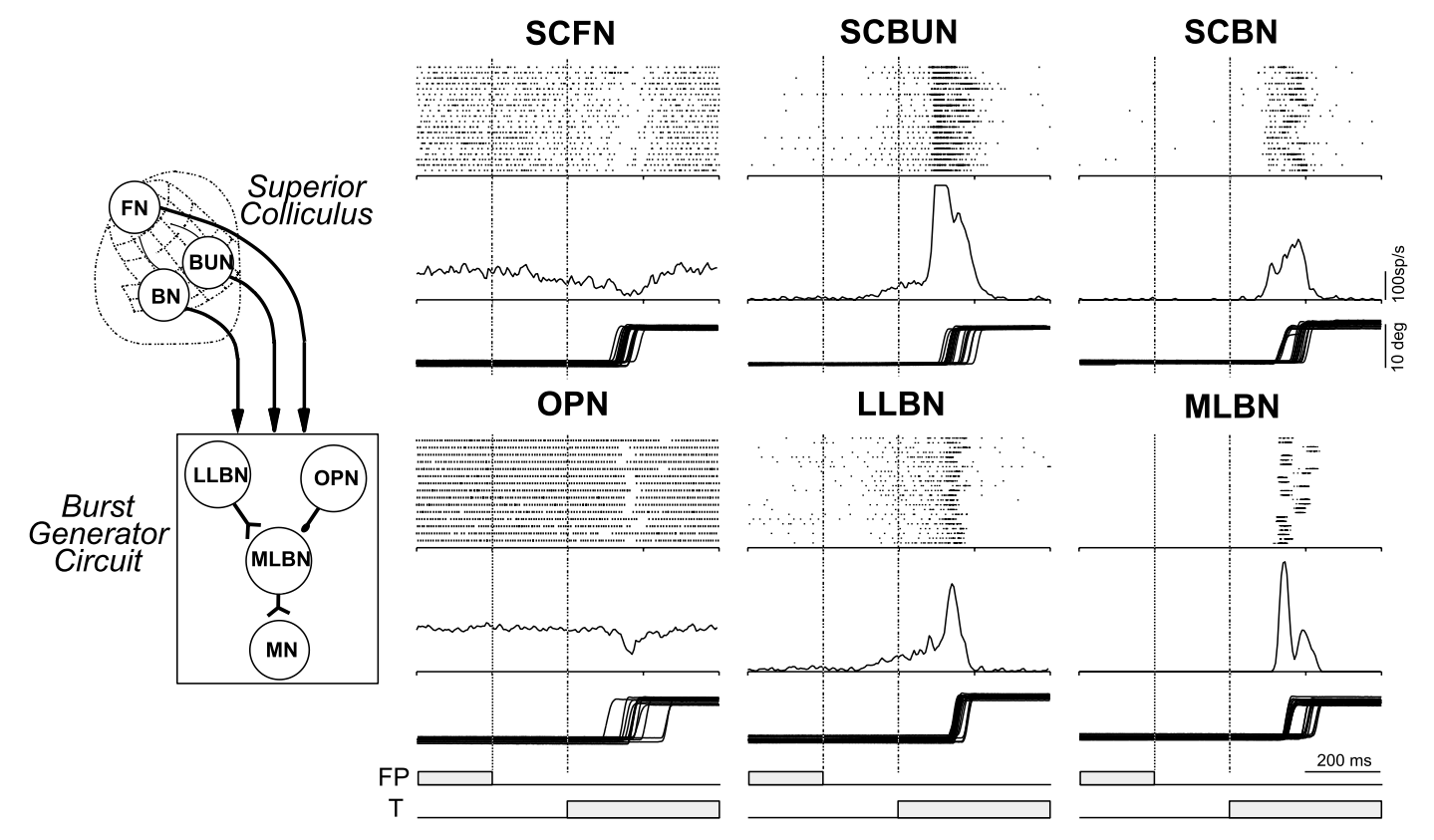

addition, the gap paradigm often results in bimodal SRT distributions, with a first mode $(\sim 100 \mathrm{~ms})$ of express saccades and a second mode ( $150 \mathrm{~ms})$ of regular saccades (Fischer and Boch 1983; Fischer and Ramsperger 1984; Fischer and Weber 1993). The latency of express saccades represents the minimal time required for sensory-motor transformation (Carpenter 1981). When the spatial location of the saccade target and the probability of its presentation is varied, it can be demonstrated that the disengagement of fixation afforded by the gap accounts for a general gap effect. However, the introduction of the gap period does not guarantee that express saccades will be generated. Rather, express saccade occurrence is determined by factors such as predictability in the location and timing of appearance of the saccadic target (Paré and Munoz 1996). Accordingly, we hypothesised that advanced motor preparation is primarily responsible for the occurrence of express saccades, which may be caused mainly by neuronal changes restricted to specific loci, coding for the trained movements, in a neural map of saccades such as the SC (Paré and Munoz 1996).

\section{The gap saccade paradigm: General discharge characteristics of neuronal classes}

To gain insight into how the brain controls saccadic initiation and identify neural correlates of the gap effect and neural mechanisms leading to the generation of express and regular saccades, we recorded activity from several different classes of neurons in the SC intermediate layers and reticular formation while monkeys performed the gap saccade task. Figure 3 shows representative examples of the activity patterns that we encountered. In these experiments, the gap duration usually varied from $0-800 \mathrm{~ms}$ and the target appeared randomly either to the right or left of central fixation, dictated by the response field of the neuron under study. The data in Fig. 3 illustrate only $200 \mathrm{~ms}$ gap trials with the target appearing 10 degrees right of fixation. The SC fixation-related neurons (SCFN) were tonically active during visual fixation, but reduced their activity about $100 \mathrm{~ms}$ into the gap period before pausing completely for the ensuing saccades. Reciprocally, the SC saccade-related neurons were silent during visual fixation and discharged a high frequency burst of action potentials for saccades into their response field. Moreover, during the gap period, some of these neurons, the build-up neurons (SCBUN), additionally displayed low-frequency pre-target discharges, while others, the burst neurons (SCBN), remained silent (Munoz and Wurtz 1995a). This initial classification scheme may be somewhat artificial and a continuum may exist between these cell types (Scudder et al. 1996; Dorris and Munoz 1998).

In the reticular formation, OPN continue to discharge at the same tonic rate during visual and non-visual fixation (Fig. 3). They do not exhibit the gap-related reduction in activity observed in SCFN (Everling et al. 1998b). In comparison, LLBN display low-frequency pre-target activity during the gap period very similar to that of SCBUN. MLBN lack such gap-related activity, and therefore more closely resemble the SCBN. How do OPN maintain their tonic discharge during the gap period? We have hypothesised that OPN receive excitatory inputs from SCFN and SCBUN (Everling et al. 1998b). Increased input from SCBUN occurs when SCFN input is reduced. A constant input onto the OPN 
Fig. 4. (A) Population response of 31 SCFN and 15 SCBUN for a gap duration of $600 \mathrm{~ms}$. (B) Plot of percentage of saccades evoked by microstimulation of the $\mathrm{SC}(300 \mathrm{~Hz}$ at threshold current, defined as $50 \%$ responses for $0 \mathrm{~ms}$ gap duration) versus gap duration. (C) Plot of mean saccadic reaction time (SRT) versus gap duration. (D) Plot of percentage of express saccades versus gap duration.
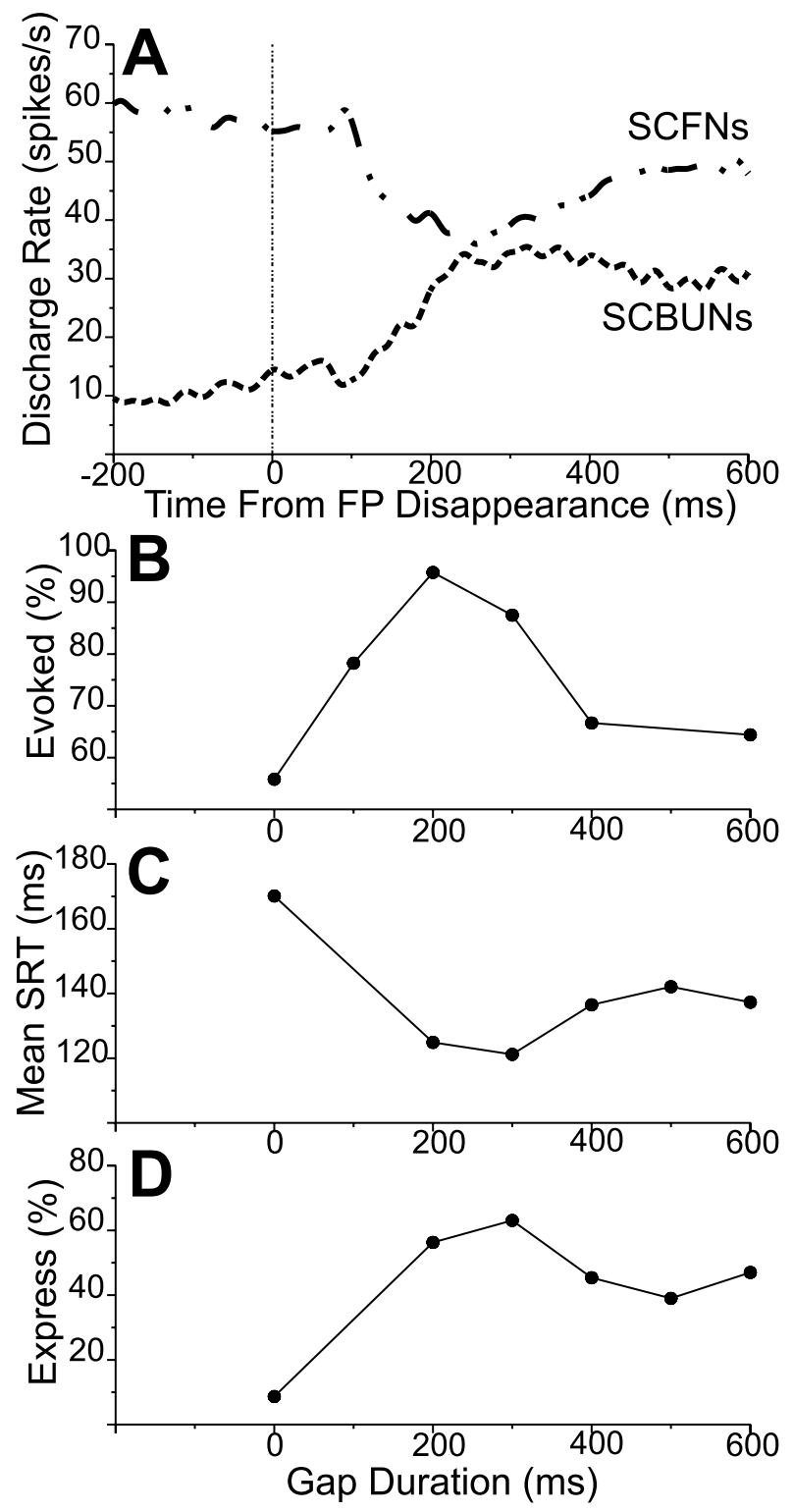

ensure that their high tonic discharge continues during the gap period and that, via their potent inhibition of MLBN, low-frequency pre-target signals do not trigger a saccade prematurely (Fig. 1C).

\section{Neural substrates of fixation disengagement}

It is widely recognised that the general reduction in SRT observed in the gap saccade task may be due to a disengagement of the fixation system afforded by the disappearance of the visual fixation point. Given the gap-related decrease in activity of SCFN and its possible consequence on the excitability of saccade-related neurons, we hypothesised that it constitutes a neural substrate of fixation disengagement (Dorris and Munoz 1995). To further examine the behaviour of these neurons in the gap saccade task, we detail in Fig. 4A the average time course of the activation of a sample of SCFN during a long duration gap (600 ms). From a relatively stable rate of $\sim 60$ spikes/s during visual fixation, the average activation declines $\sim 100 \mathrm{~ms}$ following the fixation point disappearance. This activity reaches a minimum 200-300 ms into the gap before rising toward a sustained level slightly less than during visual fixation. Consistent with the local inhibitory network hypothesis, the activation of SCFN and SCBUN are reciprocal. The average activation of SCBUN is minimal during visual fixation but starts increasing $\sim 100 \mathrm{~ms}$ following the fixation point disappearance to reach a maximum $\sim 250 \mathrm{~ms}$ into the gap period and is maintained at a high sustained level for the remainder of the gap. It remains to be determined whether the changes in SCFN activity could be responsible for the changes in SCBUN activity, thereby explaining the short SRT observed in the gap saccade task.

Microstimulation of SC saccade-related neurons with a train of stimulation pulses elicits saccadic eye movements whose metrics are remarkably similar to natural saccades (Robinson 1972). However, when a near-threshold train of microstimulation is employed, the probability of evoking a saccade depends on the presumed state of excitability of the local neurons (Sparks and Mays 1983). Thus, the significance of the putative changes in the excitability of SC neurons related to fixation release can be readily investigated with this experimental tool. To estimate the time course of the changes in neuronal excitability at different "gap" times relative to the disappearance of a fixation point, we applied a train of stimulation pulses at threshold current (eliciting a saccade on $\sim 50 \%$ of $0 \mathrm{~ms}$ gap trials) on $25 \%$ of the trials within a block in lieu of presenting the target stimulus (Fig. 4B). Paralleling the time course of SCFN and SCBUN excitability, the probability of eliciting a saccade increases substantially with the introduction of the gap and it is optimal for 200-ms gap trials. This observation reveals that the changes in excitability within the SC that occur during the evolution of the gap period do indeed influence the ability of saccade-related neurons to trigger saccades.

Our hypothesis that pre-target SC neuronal activation influences SRT are further bolstered by other relationships observed in behavioural measurements. Figure 4C and D shows how varying the duration of the gap period between 0 and $600 \mathrm{~ms}$ affects the mean SRT and the percentage of express saccades following presentation of an eccentric target. Mean SRT follows a profile similar to the discharge of SCFN, being highest for a $0 \mathrm{~ms}$ gap and lowest for gaps of 200-300 ms (Fig. 4C). The percentage of express saccades is equally influenced by the duration of the gap period (Fig. 4D), and closely follows the shape of the SCBUN activation. However, as mentioned, the fixation disengagement afforded by the gap does not provide sufficient spatial specificity to account for the occurrence of express saccades. According to our motor preparation hypothesis for express saccade generation (Paré and Munoz 1996), topographically localised changes in pre-target neuronal activity of SCBUN may represent the required motor preparation signal. 
Fig. 5. (A) Discharge of a single SCBUN in three separate blocks of trials in which the probability of a saccade being generated into the response field of the neuron was varied between 50\% (dashed line), 100\% (solid line), and 0\% (dotted line). (B) Significant negative correlation between the level of pre-target activity (sampled 50-60 ms after target appearance; see Dorris and Munoz 1998) and the subsequent saccadic reaction time. Each data point from a single trial.

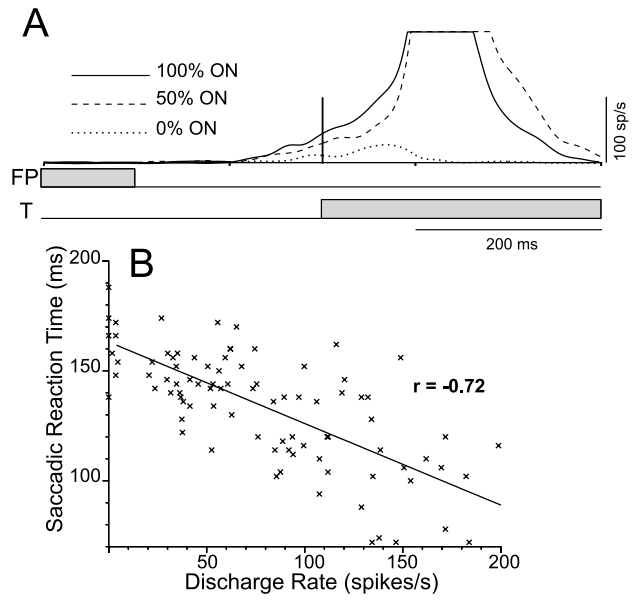

\section{Neural substrates of motor preparation}

Requin and colleagues (Requin et al. 1990; Riehle and Requin 1989, 1993) established three criteria for labelling changes in neuronal activity as related to motor preparation. First, the changes in neuronal activity must occur in advance of the movement, during a warning period. Second, the level of discharge of a neuron must follow the likelihood that the movement being produced involves that neuron. Third, and most importantly, these changes in activity must predict some attribute of motor performance (e.g., SRT).

To determine if the SC pre-target activity fulfilled these criteria for motor preparation, we manipulated the probability of the target appearing in the response fields of SCBUN while monkeys performed the gap saccade paradigm with a $200 \mathrm{~ms}$ gap duration (Dorris and Munoz 1998). Figure 5A shows how the discharge of a single SCBUN was altered by changes in the probability of saccades being directed into its response field. The pre-target activity of the neuron increased $\sim 100 \mathrm{~ms}$ into the gap period (thus fulfilling the first criterion of motor preparation) and then the neuron discharged a high frequency burst of action potentials for saccades into its response field (Fig. 5A). The level of low frequency pre-target activity was greater when the probability of a saccade being generated into the response field of the neuron was increased from $50 \%$ of the trials within a block to $100 \%$ of the trials within a block, and was reduced when the probability was switched to $0 \%$. Therefore, the magnitude of the pre-target activity varied systematically with saccadic probability, thus fulfilling the second criterion of motor preparation.

To test whether the intensity of the pre-target activity was related to SRT, we measured the activity of the same neuron immediately before the target-related information reached the $\mathrm{SC}$ and, in Fig. 5B, we plot its value as a function of
Fig. 6. Pre-target neuronal activity is shaped by past experience. (A) Spike density functions are aligned on target appearance after a $200 \mathrm{~ms}$ gap period in the gap saccade paradigm. (B) The pre-target activity is segregated based on whether the previous saccade $(\mathrm{N}-1)$ was compatible (thick line) or incompatible (thin line) with the neuron's response field. (C) The pre-target activity is segregated based on whether the previous two saccades $(\mathrm{N}-1$ and $\mathrm{N}-2$ ) were compatible (thick line) or incompatible (thin line) with the response field of the neuron.

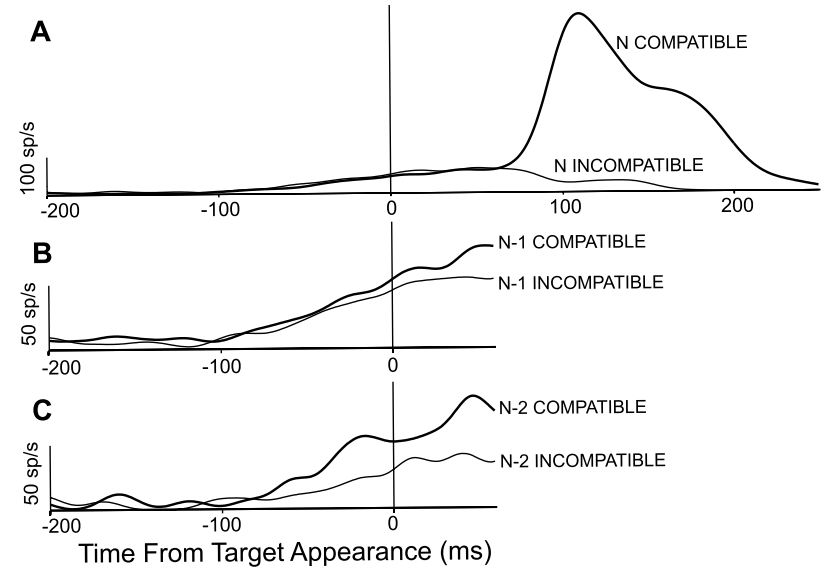

SRT on a trial-by-trial basis. Using this analysis, we have demonstrated that such a significant negative correlation between pre-target discharge rate and SRT exists for many SCBUN (Dorris et al. 1997, 2000; Dorris and Munoz 1998; Everling et al. 1999). However, similar analyses with SCFN and OPN failed to reveal a consistent relationship between pre-target activity and SRT (Dorris et al. 1997; Everling et al. 1998b). Thus, because the level of pre-target build-up activity begins during the gap period, varies with saccadic probability, and predicts SRT, we believe this activity codes for saccadic preparation.

\section{Is motor preparation a memory of past experience?}

The data illustrated in Fig. 5 show that when saccadic probability changed across blocks of trials, it influenced the level of pre-target activity of SCBUN. It is therefore possible that the level of pre-target activity is somehow influenced by previous events. To understand this phenomenon, we evaluated how this change in neuronal activity and the corresponding SRT vary as a function of trial history (Dorris et al. 2000). Figure 6A shows the discharge of a SCBUN in the gap saccade task with saccadic probability for the block of trials fixed at $50 \%$ in the neuron's response field and $50 \%$ to the opposite side. Note that the subsequent direction of the saccade (compatible, into response field; incompatible, into opposite hemifield) did not influence the level of discharge during the gap period (Fig. 6A). This was expected given that in this condition these neurons presumably cannot predict target location. These data are resorted based upon whether the previous trial (N-1) was compatible or incompatible with the neuron's response field and reveals that the previous trial influenced the subsequent level of pre-target activity (Fig. 6B). When these same data are resorted again based upon whether the previous two trials were compatible or incompatible, this sequential effect was accentuated 
Fig. 7. (A) Mean SRT as a function of the sequence of previous saccades. Mean SRT for the current saccade is shown irrespective of previous saccades $(\mathrm{N})$ or based on the compatibility of the metrics of the previous saccade $(\mathrm{N}-1)$ or previous two saccades (N-2) with the current saccade. (B) Distribution of pre-target neuronal activity as a function of the sequence of previous saccades. The current mean neuronal activity is shown irrespective of the location of the previous saccades $(\mathrm{N})$ or based on the compatibility of the previous saccade $(\mathrm{N}-1)$ or previous two saccades (N-2) with each neuron's response field. C, compatible; I, incompatible.

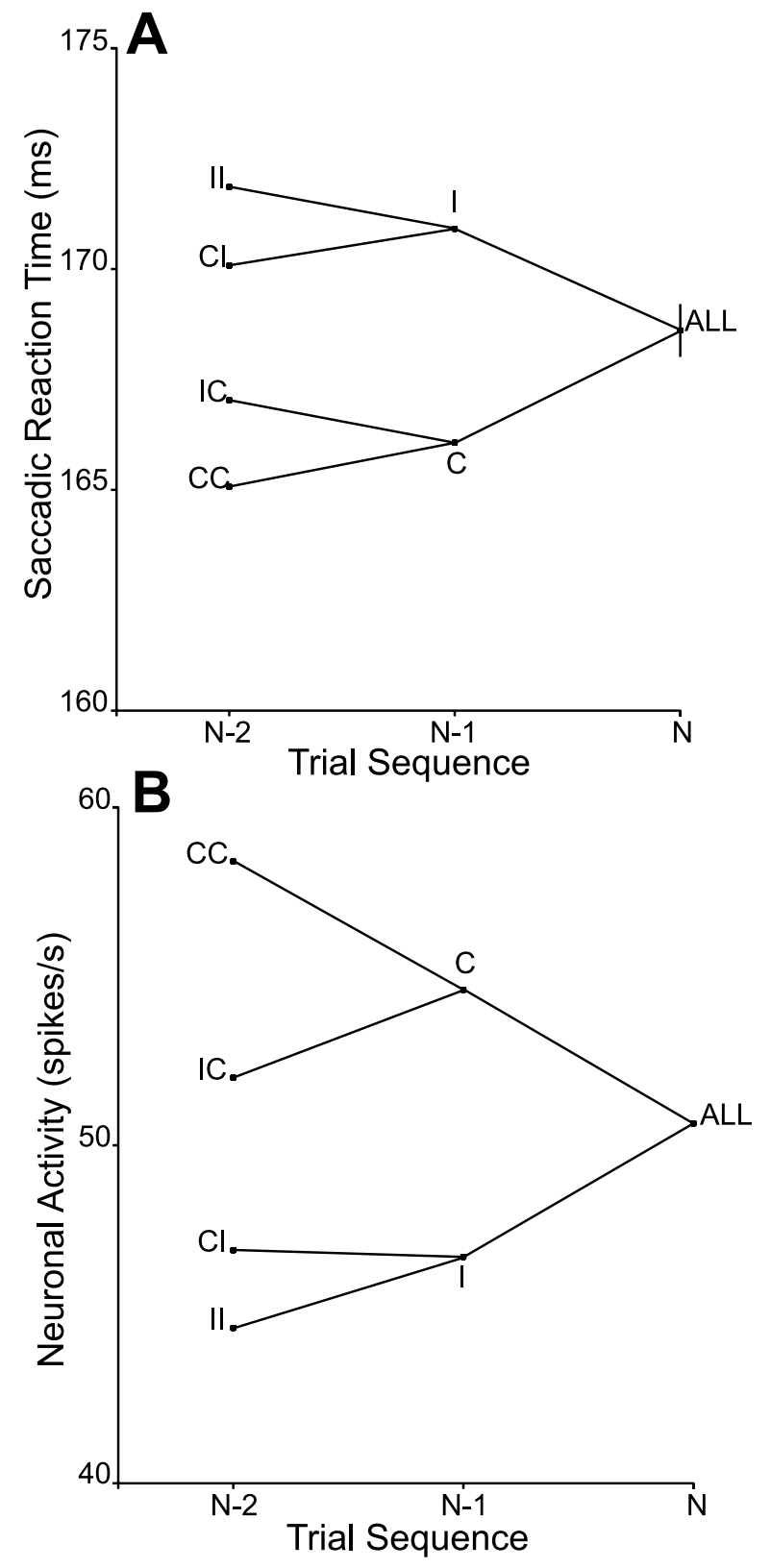

(Fig. 6C). In other words, the pre-target activity was potentiated by the repetition of compatible trials and depleted by the repetition of incompatible trials.

The relationship between collicular pre-target activity and SRT was maintained in the configuration of the sequential
Fig. 8. Discharge of a SCBN (top) and SCBUN (bottom) in the delayed saccade task used to dissociate temporally stimulus- and saccade-related activation. Both neurons discharge two bursts of action potentials: one time-locked to appearance of the visual stimulus in the response field (left panels), the second burst is time-locked to saccade onset (right panels). Note that during the delay period, the SCBN was nearly silent, while the SCBUN was active at a low frequency.

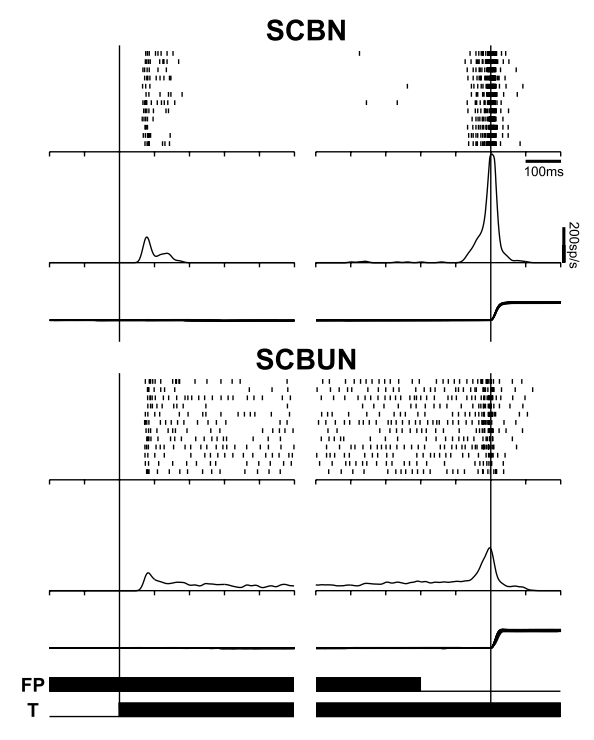

pattern of changes in the SRT distribution (Fig. 7A) and neuronal activity of the population of neurons (Fig. 7B). Thus, the same neuronal activity both predicted future behaviour and reflected the past experience. We therefore argue that the neural processes underlying behavioural responses cannot be isolated in a single trial but must be recognised in the context of trial history.

\section{Visual to oculomotor transition}

The time required to initiate a saccade to a suddenly appearing target generally exceeds the afferent conduction time for visual information to reach the oculomotor system, the minimal sensory-motor processing time and the efferent time for the saccadic motor command to recruit the ocular motoneurons (Carpenter 1981). When monkeys look toward an eccentric visual target that appears suddenly in the peripheral visual field, SCBUN and SCBN usually discharge two bursts of action potentials. To dissociate temporally a neuron's response to visual stimulation from its motor activation, we employed a delayed saccade task, wherein the monkey maintains fixation on a central fixation point even after an eccentric target appears and the delayed disappearance of the fixation point signals the animal to make a saccade to the eccentric target. Many SCBN and SCBUN discharge a transient response immediately following the sudden appearance of the eccentric target in their response field (Fig. 8, left panel) and they discharge a subsequent motor response time-locked to the occurrence of the saccade into their response field (Fig. 8, right panel). The stimulus-related activation of these neurons is almost always less than their saccade-related activation (Dorris et al. 1997), and it is usually considered to be a simple sensory response. 
Fig. 9. Difference in discharge (spike density waveform) of a SCFN, SCBUN, SCBN, OPN, LLBN, and MLBN between express-latency (solid traces) and regular-latency (dashed traces) saccades in the gap saccade task. Note that the SCBUN and SCBN discharge two bursts for regular saccades, but only one burst for express saccades. Note also that the SCBUN and LLBN had more pre-target activity preceding express saccades.

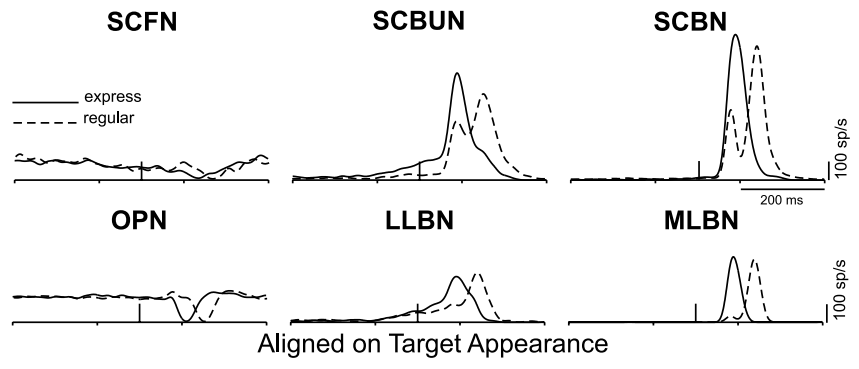

However, given that the activation of these neurons can potentially reach the brainstem saccade generator circuit, it is more reasonable to think of the stimulus-related activation as a failed motor activation. This view is consistent with models of saccadic initiation in which a threshold level of activity must be surpassed to trigger a saccade (Carpenter and Williams 1995; Hanes and Schall 1996; Dorris et al. 1997; Ratcliff et al. 1999). In addition to phasic stimulus-locked activation, sub-threshold sustained activity can also be observed during the delay period of the delayed saccade task, especially in the neurons (SCBUN) that display a build-up of activity in the gap saccade task (Munoz and Wurtz $1995 a)$.

\section{Visual to oculomotor discharges: The case of express saccades}

Express saccades are a separate mode in the distribution of SRTs (see Fig. 2C) whose latency approaches the minimal sensory afferent and motor efferent conduction times (Fischer and Weber 1993). Given their special nature do they conform to threshold models of saccadic initiation? Figure 9 contrasts the mean discharge rate of individual neurons recorded in both the SC and the pontine reticular formation during the execution of express and regular saccades. There are two important observations to make. First, prior to the execution of express saccades, SCBUN and LLBN both have a higher level of pre-target activity preceding target appearance in the gap paradigm. This is consistent with the hypothesis that higher pre-target activity codes faster SRT (Fig. 5B). The second important observation is that, for SCBUN and SCBN, there are two bursts of action potentials after target appearance for regular saccades, a small stimulus-related burst and a second larger motor-related burst, but only one burst for express saccades that is equally aligned on both stimulus presentation and saccade onset. For express saccades, it is as if the two bursts of activity merged into one visuo-motor burst (Edelman and Keller 1996; Dorris et al. 1997).

Our hypothesis is that the pre-target activity that occurs in the gap paradigm moves the system closer to the threshold for saccade initiation. When the transient stimulus-related burst of activity arrives in the SC it is added to the early
Fig. 10. Discharge of a SCBUN in the anti-saccade task. The eccentric stimulus appeared in the neuron's response field and the correct response (A) was to look to the opposite side, while the incorrect response (B) consisted of looking toward the stimulus. C) The spike density waveforms for correct (thin line) and error (thick line) responses are superimposed to reveal a significant difference in pre-target activity between correct and error responses. Circles in rasters denote saccade onset.
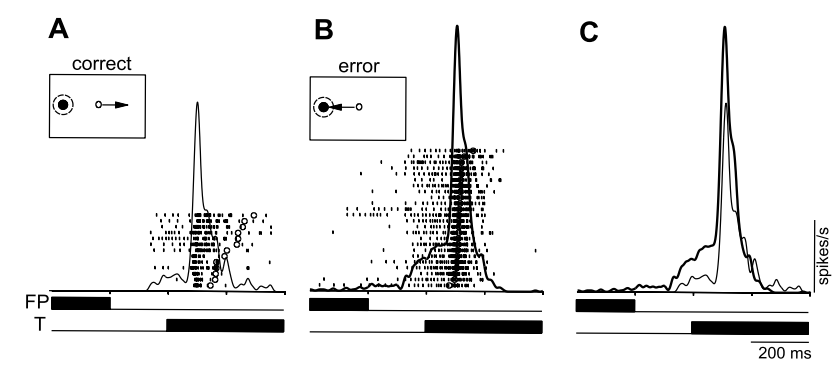

pre-target activity. If this early pre-target activity is high enough then the visual burst drives the system over the threshold and an express saccade is triggered. If the pre-target activity is low, then the stimulus-related burst does not reach the threshold for saccadic initiation and the system must wait for a later signal which delays saccadic initiation and produces a regular-latency saccade. According to our hypothesis, two events are required for express saccades: a high level of pre-target activity and a transient response caused by either the appearance of a new target or motion of an existing target. Because these conditions occur often in the natural environment, we argue that express saccade generation forms an important part of any visual search and they are not simply an epiphenomenon limited to the laboratory (see also Sommer 1994).

To further test the threshold models of saccadic initiation, we have used the anti-saccade task (Everling et al. 1998a, 1999). We hypothesised that a high level of pre-stimulus activity in the SC, which shortens SRT, would increase saccadic errors directed to the stimulus by allowing the stimulus-related burst to trigger a reflexive saccade. To test this hypothesis, we recorded the activity of SCBUN while monkeys performed a task with randomly interleaved pro-saccade (saccade toward the stimulus) and anti-saccade (saccade away from the stimulus to the opposite side) trials. In addition, the eccentric stimulus appeared with equal probability either in the response field of the neuron, or on the opposite side. Figure 10 shows the discharge of a SCBUN during the execution of correct anti-saccades and erroneous pro-saccades triggered in the anti-saccade condition. The stimulus was presented in the neuron's response field so that the opposite SC should drive the anti-saccade (Everling et al. 1999). The appearance of the visual stimulus triggers a transient phasic response in the neuron. On error trials, excessive pre-target activity during the gap allows the stimulus-related response to exceed a threshold and trigger an erroneous pro-saccade. Most importantly, note that almost all of the erroneous pro-saccades are triggered at express saccade latencies (Everling et al. 1998a). On correct trials the pre-target activity is reduced prior to stimulus appearance so that the transient stimulus-related burst does not exceed saccade 
threshold. Once again the level of pre-target activity predicts not only SRT, but also the selection of the saccade; too much pre-target activity leads to the initiation of a visually triggered reflexive saccade. To initiate a voluntary anti-saccade, pre-target activity within the SC must be reduced.

\section{Conclusions}

In this article, we have focused discussion upon pre-target factors that influence movement initiation. It should be stressed emphatically that these are not the only important factors that determine behaviour. Certainly, in cases where there exists high uncertainty of upcoming events (Hanes and Schall 1996; Basso and Wurtz 1997; Hanes and Paré 1998) or high cognitive loads such as during visual search or discrimination tasks (Schall and Thompson 1999) there is little pre-target information that can be gathered and therefore little pre-target neural processing can occur. In these cases, the variability in reaction times is dominated by post-target processes.

Warning signals like those provided in the gap saccade paradigm by the gap period lead to systematic changes in excitability of neurons within the superior colliculus and brainstem reticular formation that subsequently influence SRT. This may be analogous to the preparatory steps taken by a sprinter when the starter at a race announces "On your mark! Get set!" The higher the level of preparation, the faster the subsequent reaction time. The trade-off is that in a heightened state of preparation, the system is very close to threshold to initiate a response and there is no time for post-stimulus processing other than providing a GO signal.

Understanding the brainstem saccadic initiation circuitry acts as a foundation on which to study the influences of higher cognitive inputs to the system. Inputs from the cortex and basal ganglia are likely to play a crucial role in determining the excitability levels of the neuronal elements in the system to influence the behavioural states of visual fixation and motor preparation. For example, recent studies have investigated the role of the frontal eye fields in saccadic initiation and described mechanisms contributing to movement initiation (Hanes and Schall 1996; Everling and Munoz 2000). Using rigorous behavioural manipulations with quantitative physiological measurements can lead to a better understanding of the neural basis of movement initiation.

\section{Acknowledgements}

We thank Ann Lablans, Kim Moore, and Dave Hamburger for outstanding technical assistance. This work was supported by the Medical Research Council of Canada. D.P.M. is a Scientist of the MRC.

\section{References}

Basso, M.A., and Wurtz, R.H. 1997. Modulation of neuronal activity by target uncertainty. Nature (London) 389: 66-69.

Büttner-Ennever, J.A., Horn, A.K., Henn, V., and Cohen, B. 1999. Projections from the superior colliculus motor map to omnipause neurons in monkey. J. Comp. Neurol. 413: 550-567.

Carpenter, R.H.S. 1981. Oculomotor procrastination. In Eye movements: cognition and visual perception. Edited by D.F. Fischer and R.A. Monty. Erlbaum: Hillsdale, N.J. pp. 237-246.
Carpenter, R.H., and Williams, M.L. 1995. Neural computation of $\log$ likelihood in control of saccadic eye movements. Nature (London), 377: 59-62.

Chaturvedi, V., and Van Gisbergen, J.A. 2000. Stimulation in the rostral pole of the monkey superior colliculus: effects on vergence eye movements. Exp. Brain Res. 132: 72-78.

Cullen, K.E., and Guitton, D. 1998. Analysis of primate IBN spike trains using system identification techniques. I. Relationship To eye movement dynamics during head-fixed saccades. J. Neurophysiol. 78: 3259-3282.

Dorris, M.C., and Munoz, D.P. 1995. A neural correlate for the gap effect on saccadic reaction times in monkey. J. Neurophysiol. 73: $2558-2562$.

Dorris, M.C., and Munoz, D.P. 1998. Saccadic probability influences motor preparation signals and time to saccadic initiation. J. Neurosci. 18: 7015-7026.

Dorris, M.C., Paré, M., and Munoz, D.P. 1997. Neuronal activity in monkey superior colliculus related to the initiation of saccadic eye movements. J. Neurosci. 17: 8566-8579.

Dorris, M.C., Paré, M., and Munoz, D.P. 2000. Immediate neural plasticity shapes motor performance. J. Neurosci. 20: RC52(1-5).

Dow, B.M., Snyder, A.Z., Vautin, R.G., and Bauer, R. 1981. Magnification factor and receptive field size in foveal striate cortex of the monkey. Exp. Brain Res. 44: 213-228.

Edelman, J.A., and Keller, E.L. 1996. Activity of visuomotor burst neurons in the superior colliculus accompanying express saccades. J. Neurophysiol. 76: 1-19.

Everling, S., and Munoz, D.P. 2000. Neuronal correlates for preparatory set associated with pro-saccades and anti-saccades in the primate frontal eye field. J. Neurosci. 20: 387-400.

Everling, S., Dorris, M.C., and Munoz, D.P. 1998a. Reflex suppression in the anti-saccade task is dependent on prestimulus neural processes. J. Neurophysiol. 80: 1584-1589.

Everling, S., Paré, M., Dorris, M.C., and Munoz, D.P. 1998b. Comparison of the discharge characteristics of brain stem omnipause neurons and superior colliculus fixation neurons in monkey: implications for control of fixation and saccade behavior. $\mathrm{J}$. Neurophysiol. 79: 511-528.

Everling, S., Dorris, M.C., Klein, R.M., and Munoz, D.P. 1999. Role of primate superior colliculus in preparation and execution of anti-saccades and pro-saccades. J. Neurosci. 19: 2740-2754.

Fischer, B., and Boch, R. 1983. Saccadic eye movements after extremely short reaction times in the monkey. Brain Res. 260: 21-26.

Fischer, B., and Ramsperger, E. 1984. Human express saccades: extremely short reaction times of goal directed eye movements. Exp. Brain Res. 57: 191-195.

Fischer, B., and Weber, H. 1993. Express saccades and visual attention. Behav. Brain Sci. 16: 533-610.

Fuchs, A.F., Kaneko, C.R., and Scudder, C.A. 1985. Brainstem control of saccadic eye movements. Annu. Rev. Neurosci. 8: 307-337.

Gandhi, N.J., and Keller, E.L. 1997. Spatial distribution and discharge characteristics of superior colliculus neurons antidromically activated from the omnipause region in monkey. J. Neurophysiol. 78: 2221-2225.

Gandhi, N.J., and Keller, E.L. 1999a. Comparison of saccades perturbed by stimulation of the rostral superior colliculus, the caudal superior colliculus, and the omnipause neuron region. J. Neurophysiol. 82: 3236-3253.

Gandhi, N.J., and Keller, E.L. 1999b. Activity of the brain stem omnipause neurons during saccades perturbed by stimulation of the primate superior colliculus. J. Neurophysiol. 82: 3254-3267. 
Glimcher, P.W., and Sparks, D.L. 1992. Movement selection in advance of action in the superior colliculus. Nature (London), 355: 542-545.

Hanes, D.P., and Paré, M. 1998. Neural control of saccade production studied with the countermanding paradigm: superior colliculus. Soc. Neurosci. Abstr. 24: 418.

Hanes, D,P., and Schall, J.D. 1996. Neural control of voluntary movement initiation. Science (Washington, D.C.), 274: 427-430.

Hepp, K., and Henn, V. 1983. Spatio-temporal recoding of rapid eye movement signals in the monkey paramedian pontine reticular formation (PPRF). Exp. Brain Res. 52: 105-120.

Hepp, K., Henn, V., Vilis, T., and Cohen, B. 1989. Brainstem regions related to saccade generation. In The neurobiology of saccadic eye movements. Edited by R.H. Wurtz and M.E. Goldberg. Elsevier: Amsterdam. pp. 105-212.

Hikosaka, O., and Wurtz, R.H. 1983. Visual and oculomotor functions of monkey substantia nigra pars reticulata. IV. Relation of substantia nigra to superior colliculus. J. Neurophysiol. 49: 1285-1301.

Istvan, P.J., Dorris, M.C., and Munoz, D.P. 1994. Functional identification of neurons in the monkey superior colliculus projecting to the paramedian pontine reticular formation. Soc. Neurosci. Abstr. 20: 141.

Jüttner, M., and Wolf, W. 1992. Occurrence of human express saccades depends on stimulus uncertainty and stimulus sequence. Exp. Brain Res. 89: 678-681.

Keller, E.L. 1974. Participation of medial pontine reticular formation in eye movement generation in monkey. J. Neurophysiol. 37: $316-332$.

Keller, E.L. 1991. The brainstem. In Vision and visual dysfunction, eye movements. Edited by R.H.S. Carpenter. MacMillan Press. pp. 200-223.

Kingstone, A., and Klein, R.M. 1993. Visual offsets facilitate saccadic latency: does predisengagement of visuospatial attention mediate the gap effect? J. Exp. Psychol. Hum. Percept. Perform. 19: 1251-1265.

Krauzlis, R.J., Basso, M.A., and Wurtz, R.H. 1997. Shared motor error for multiple eye movements. Science (Washington, D.C.), 276: 1693-1695.

Leigh, R.J., and Zee, D.S. 1999. The neurology of eye movements. Philadelphia: F.A. Davis Company. p. 646.

Luschei, E.S., and Fuchs, A.F. 1972. Activity of brain stem neurons during eye movements of alert monkeys. J. Neurophysiol. 35: 445-461.

Mays, L.E., and Sparks, D.L. 1980. Dissociation of visual and saccade-related responses in superior colliculus neurons. J. Neurophysiol. 43: 207-232.

Mohler, C.W., and Wurtz, R.H. 1976. Organization of monkey superior colliculus: intermediate layer cells discharging before eye movements. J. Neurophysiol. 39: 722-744.

Moschovakis, A.K., Karabelas, A.B., and Highstein, S.M. $1988 a$. Structure-function relationships in the primate superior colliculus. I. Morphological classification of efferent neurons. J. Neurophysiol. 60: 232-262.

Moschovakis, A.K., Karabelas, A.B., and Highstein, S.M. 1988 b. Structure-function relationships in the primate superior colliculus. II. Morphological identity of presaccadic neurons. J. Neurophysiol. 60: 263-302.

Moschovakis, A.K., Scudder, C.A., and Highstein, S.M. 1996. The microscopic anatomy and physiology of the mammalian saccadic system. Prog. Neurobiol. 50: 133-254.

Moschovakis, A.K., Kitama, T., Dalezios, Y., Petit, J., Brandi,
A.M., and Grantyn, A.A. 1998. An anatomical substrate for the spatiotemporal transformation. J. Neurosci. 18: 10219 - 10229.

Munoz, D.P., and Guitton, D. 1989. Fixation and orientation control by the tecto-reticulo-spinal system in the cat whose head is unrestrained. Revue Neurologique, 145: 567-579.

Munoz, D.P., and Guitton, D. 1991. Control of orienting gaze shifts by the tectoreticulospinal system in the head-free cat. II. Sustained discharges during motor preparation and fixation. J. Neurophysiol. 66: 1624-1641.

Munoz, D.P., and Istvan, P.J. 1998. Lateral inhibitory interactions in the intermediate layers of the monkey superior colliculus. J. Neurophysiol. 79: 1193-1209.

Munoz, D.P., and Wurtz, R.H. 1993a. Fixation cells in monkey superior colliculus I. Characteristics of cell discharge. J. Neurophysiol. 70: 559-575.

Munoz, D.P., and Wurtz, R.H. 1993b. Fixation cells in monkey superior colliculus. II. Reversible activation and deactivation. J. Neurophysiol. 70: 576-589.

Munoz, D.P., and Wurtz, R.H. 1995a. Saccade-related activity in monkey superior colliculus I. Characteristics of burst and buildup cells. J. Neurophysiol. 73: 2313-2333.

Munoz, D.P., and Wurtz, R.H. 1995b. Saccade-related activity in monkey superior colliculus II. Spread of activity during saccades. J. Neurophysiol. 73: 2334-2348.

Munoz, D.P., Guitton, D., and Pelisson, D. 1991a. Control of orienting gaze shifts by the tectoreticulospinal system in the head-free cat. III. Spatiotemporal characteristics of phasic motor discharges. J. Neurophysiol. 66: 1642-1666.

Munoz, D.P., Pelisson, D., and Guitton, D. 1991b. Movement of neural activity on the superior colliculus motor map during gaze shifts. Science (Washington, D.C.), 251: 1358-1360.

Paré, M., and Guitton, D. 1994. The fixation area of the cat superior colliculus: effects of electrical stimulation and direct connection with brainstem omnipause neurons. Exp. Brain Res. 101: 109-122.

Paré, M., and Munoz, D.P. 1996. Saccadic reaction time in the monkey: advanced preparation of oculomotor programs is primarily responsible for express saccade occurrence. J. Neurophysiol. 76: 3666-3681.

Paré, M., and Wurtz, R.H. 1997. Monkey posterior parietal cortex neurons antidromically activated from superior colliculus. J. Neurophysiol. 78: 3493-3497.

Perry, V.H., and Cowey, A. 1985. The ganglion cell and cone distributions in the monkey's retina: implications for central magnification factors. Vision Res. 25: 1795-1810.

Quaia, C., and Optican, L.M. 1998. Commutative saccadic generator is sufficient to control a 3-D ocular plant with pulleys. J. Neurophysiol. 79: 3197-3215.

Ratcliff, R., Van Zandt, T., and McKoon, G. 1999. Connectionist and diffusion models of reaction time. Psychol. Rev. 106: 261-300.

Raybourn, M.S., and Keller, E.L. 1977. Colliculoreticular organization in primate oculomotor system. J. Neurophysiol. 40: 861-878.

Requin, J., Lecas, J.C., and Vitton, N. 1990. A comparison of preparation-related neuronal activity changes in the prefrontal, premotor, primary motor and posterior parietal areas of the monkey cortex: preliminary results. Neurosci. Lett. 111: 151-156.

Reuter-Lorenz, P.A., Hughes, H.C., and Fendrich, R. 1991. The reduction of saccadic latency by prior offset of the fixation point: an analysis of the gap effect. Percept. Psychophys. 49: 167-175.

Riehle, A., and Requin, J. 1989. Monkey primary motor and premotor cortex: single-cell activity related to prior information 
about direction and extent of an intended movement. J. Neurophysiol. 61: 534-549.

Riehle, A., and Requin, J. 1993. The predictive value for performance speed of preparatory changes in neuronal activity of the monkey motor and premotor cortex. Behav. Brain Res. 53: 35-49.

Robinson, D.A. 1972. Eye movements evoked by collicular stimulation in the alert monkey. Vision Res. 12: 1795-1808.

Robinson, D.L., and McClurkin, J.W. 1989. The visual superior colliculus and pulvinar. In The neurobiology of saccadic eye movements. Elsevier: Amsterdam. pp. 337-360.

Ross, L.E., and Ross, S.M. 1980. Saccade latency and warning signals: stimulus onset, offset, and change as warning events. Percept. Psychophys. 27: 251-257.

Saslow, M.G. 1967. Effects of components of displacement-step stimuli upon latency of saccadic eye movements. J. Opt. Soc. Am. 57: 1024-1029.

Schall, J.D., and Thompson, K.G. 1999. Neural selection and control of visually guided eye movements. Annu. Rev. Neurosci. 22: 241-259.

Schiller, P.H., and Koerner, F. 1971. Discharge characteristics of single units in superior colliculus of the alert rhesus monkey. J. Neurophysiol. 34: 920-936.

Scudder, C.A. 1988. A new local feedback model of the saccadic burst generator. J Neurophysiol 59: 1455-1475.

Scudder, C.A., Moschovakis, A.K., Karabelas, A.B., and Highstein, S.M. 1996. Anatomy and physiology of saccadic long-lead burst neurons recorded in the alert squirrel monkey. I. Descending projections from the mesencephalon. J. Neurophysiol. 76: 332-352.

Segraves, M.A., and Goldberg, M.E. 1987. Functional properties of corticotectal neurons in the monkey's frontal eye field. J. Neurophysiol. 58: 1387-1419.

Sommer, M.A. 1994. Express saccades elicited during visual scan in the monkey. Vision Res. 34: 2023-2038.
Sparks, D.L. 1978. Functional properties of neurons in the monkey superior colliculus: coupling of neuronal activity and saccade onset. Brain Res. 156: 1-16.

Sparks, D.L., and Mays, L.E. 1980. Movement fields of saccade-related burst neurons in the monkey superior colliculus. Brain Res. 190: 39-50.

Sparks, D.L., and Mays, L.E. 1983. Spatial localization of saccade targets. I. Compensation for stimulation-induced perturbations in eye position. J. Neurophysiol. 49: 45-63.

Sparks, D.L., Holland, R., and Guthrie, B.L. 1976. Size and distribution of movement fields in the monkey superior colliculus. Brain Res. 113: 21-34.

Strassman, A., Evinger, C., McCrea, R.A., Baker, R.G., and Highstein, S.M. 1987. Anatomy and physiology of intracellularly labelled omnipause neurons in the cat and squirrel monkey. Exp. Brain Res. 67: 436-440.

Van Essen, D.C., Newsome, W.T., and Maunsell, J.H. 1984. The visual field representation in striate cortex of the macaque monkey: asymmetries, anisotropies, and individual variability. Vision Res. 24: 429-448.

Van Gisbergen, J.A., Robinson, D.A., and Gielen, S.A. 1981. A quantitative analysis of generation of saccadic eye movements by burst neurons. J. Neurophysiol. 45: 417-442.

Waitzman, D.M., Ma, T.P., Optican, L.M., and Wurtz, R.H. 1991. Superior colliculus neurons mediate the dynamic characteristics of saccades. J. Neurophysiol. 66: 1716-1737.

Wurtz, R.H., and Goldberg, M.E. 1971. Superior colliculus responses related to eye movement in awake monkeys. Science (Washington, D.C.), 171: 82-84.

Wurtz, R.H., and Goldberg, M.E. 1972. Activity of superior colliculus in behaving monkey. III. Cells discharging before eye movements. J. Neurophysiol. 35: 575-586.

Wurtz, R.H., and Goldberg, M.E. 1989. The neurobiology of saccadic eye movements. Elsevier: Amsterdam. p. 415. 